\title{
Adrien Paschoud, Le monde amérindien au miroir des "Lettres édifiantes et curieuses»
}

\section{Simón Gallegos Gabilondo}

\section{(2) OpenEdition}

1 Journals

\section{Edizione digitale}

URL: http://journals.openedition.org/studifrancesi/7925

DOI: 10.4000/studifrancesi.7925

ISSN: 2421-5856

\section{Editore}

Rosenberg \& Sellier

\section{Edizione cartacea}

Data di pubblicazione: 1 juillet 2009

Paginazione: 396-367

ISSN: 0039-2944

\section{Notizia bibliografica digitale}

Simón Gallegos Gabilondo, «Adrien Paschoud, Le monde amérindien au miroir des «Lettres édifiantes et curieuses»", Studi Francesi [Online], 158 (LIII | II) | 2009, online dal 30 novembre 2015, consultato il 09 janvier 2021. URL: http://journals.openedition.org/studifrancesi/7925 ; DOI: https://doi.org/10.4000/ studifrancesi.7925

Questo documento è stato generato automaticamente il 9 janvier 2021.

\section{(c)}

Studi Francesi è distribuita con Licenza Creative Commons Attribuzione - Non commerciale - Non opere derivate 4.0 Internazionale. 


\title{
Adrien Paschoud, Le monde amérindien au miroir des «Lettres édifiantes et curieuses»
}

\author{
Simón Gallegos Gabilondo
}

\section{NOTIZIA}

ADRIEN PASCHOUD, Le monde amérindien au miroir des «Lettres édifiantes et curieuses», Oxford, Voltaire Foundation, 2008 («SVEC 2008:07»), pp. 229.

1 Il progetto editoriale delle Lettres édifiantes et curieuses écrites des missions étrangères par quelques missionnaires de la Compagnie de Jésus (1702-1776, 34 voll.) raccoglieva una considerevole quantità di resoconti epistolari, che offrivano al gusto per l'esotico dei lettori europei un ricco materiale sulle culture dell'Asia e dell'America come testimonianza delle missioni che i Gesuiti vi svolgevano. Questa mole d'informazioni costituiva una fonte di primo piano per la cultura letteraria e philosophique del secolo dei Lumi, alcuni dei cui grandi temi, come dimostra l'autore, si trovano spesso in una stretta, e talvolta ambigua, relazione con questo sapere dai confini sfumati. Lo studio di Paschoud, che si basa sulle lettere che riguardano il continente americano, è contraddistinto da un duplice interesse. Esso analizza lo sguardo dei missionari europei, i quali - anche se evidentemente offrono un'immagine del Nuovo Mondo filtrata attraverso la propria fede religiosa - codificano nella forma dell'epistola un sapere che può essere esplorato sia dal punto di vista delle culture dell'America intese come oggetto di conoscenza in sé stesso, sia dall'ottica di come l'ordine religioso si approcciava a tale oggetto nel contesto storico e culturale del xviII secolo. Lo studio delle Lettres si muove tra questi due oggetti di ricerca, ovvero tra i caratteri che descrivono oggettivamente le culture dell'America e il modo nel quale i Gesuiti si ponevano nei confronti di una cultura lontana e 'altra'. Il volume, inoltre, non si limita 
a considerare i contenuti di queste lettere ma fornisce anche una ricostruzione della loro ricezione nella cultura del Vecchio Continente (cap. VI, pp. 169-199).

2 La rappresentazione dell'uomo americano appare come il risultato dell'associazione tra categorie preesistenti e scoperte appurate in loco, per cui un'umanità 'nuova' viene avvicinata all'idea di una chiesa primitiva: le Lettres evidenziano anche le particolarità e 'curiosità' che questo continente poteva presentare ad osservatori che si alternano tra la fascinazione per uno stato di natura non corrotto e la condanna dei costumi che paiono loro riprovevoli, talvolta demoniaci. Nella corrispondenza dei missionari il particolare viene sostituito con l'universale e questo esercizio epistolare, talora nell'evidente incomprensione, è finalizzato a conferire un senso ad una realtà difficile da afferrare, costruendo un discorso nel quale la colonizzazione-evangelizzazione degli Americani svolge un ruolo di primo piano. Tuttavia gli stessi fenomeni - politici, economici, sociali, religiosi, umani - trovano diverse interpretazioni attraverso le epistole dei Gesuiti, e qui risiede il loro valore, in quanto rappresentano un'ampia e diversificata fonte per lo studio dell'incontro tra America ed Europa in senso storico, antropologico e filosofico, con la quale i philosophes stabiliscono un rapporto complesso. Infatti dalle Lettres non emerge soltanto una rappresentazione stereotipata in senso religioso della condizione selvaggia; vi sono, ad esempio, aspetti che evidenziano una certa comprensione dei conflitti tra diversi gruppi indigeni, della formazione di queste società e di come esse sono organizzate. Il quadro generale delle società indigene sembra così articolarsi tra le coppie di opposti ammirazione-condanna e comprensionefraintendimento, per cui pratiche diverse - che vanno dagli scambi commerciali all'antropofagia - si trovano ad oscillare tra questi poli, ed è all'interno di questa oscillazione che Adrien Paschoud colloca in modo convincente le lettere dei missionari. Paradigmatica, infine, risulta l'organizzazione politica autonoma delle reductiones (cap. IV, pp. 119-144), il cui disegno si propone di ordinare il 'caos selvaggio' salvando le anime e riscattando gli indigeni: a questo riguardo le lettere testimoniano come la storia delle idee e la storia dell'uomo si compenetrino fino al punto estremo e incerto della materializzazione di un certo tipo di utopia politico-spirituale. Oggi quelle stesse pagine ci raccontano di rischi che non possiamo trascurare, nei quali la civiltà si illude di poter infondere un inflessibile ordine al suo 'altro' - errabondo e inafferrabile - per poter realizzare se stessa in modo compiuto e definitivo. 